\title{
IDENTIFICATION OF LEFT VENTICULAR MODEL PARAMETERS
}

\author{
Herman B.K. Boom and Hessel Wijkstra
}

Biomedical Engineering Division, Department of electrical Engineering,

Twente University, 7500 AE Enschede, The Netherlands.

\section{ABSTRACT}

Simulations with a model of left ventricular pressure generation consisting of time varying Elastance, Resistance, Series-Elastance and Deactivation were fitted to pressure curves measured in the isolated rabbit ventricle. For constant ejection flows a fit with a RMS error of 2.78 $\mathrm{mmHg}$ was obtained provided that deactivation was actually incorporated in the model. Deactivation was assumed to depend linearly on end ejection pressure. Resistance was found to be independent of volume.

\section{INTRODUCTION}

It has been shown that for constant ejection flow the left ventricle can be described by an Elastance $E(t)[1]$ a Resistance $R(t)$ [2], a Series-Elastance $E_{s}(t)$ [3] and a Deactivation [4], interpreted as a time varying parallel elastance $E_{d}(t)$. The time variances in the parameters appear to obey:

$$
\mathrm{E}(\mathrm{t})=\gamma_{\mathrm{e}} \mathrm{f}(\mathrm{t}), \mathrm{R}(\mathrm{t})=\rho . \mathrm{f}(\mathrm{t}), \mathrm{E}_{\mathrm{s}}=\gamma_{\mathrm{S}} \mathrm{f}(\mathrm{t}), \mathrm{E}_{\mathrm{d}}=\gamma_{\mathrm{d}} . \mathrm{f}(\mathrm{t}) .
$$

Thus a common time function $f(t)$ is involved, which corresponds to the time course of isovolumic pressure.

The validity of this model has been derived from different and restricting experiments specifically adapted to measurement of the respective parameters. In this paper we address the question whether the complete model can accurately and non-redundantly describe ventricular pressure before, during and after constant flow ejection. Thus model simulations are fitted to experimental pressure curves, and model parameters are collectively identified.

\section{THEORY}

The above-ive-element model is simulawd by numerically solving the finite difference equation

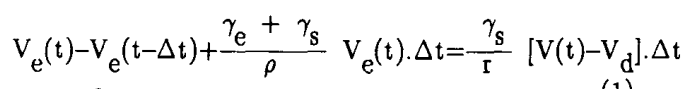

Where $V(t)$ is ventricular volume, $V_{e}(t)$ the volume of the elastance compartment and $\Delta t$ is the time difference used. $\mathrm{V}_{\mathrm{d}}$ is residual volume. Resistance $\rho$ is admittedly volume dependent:

$$
\rho(\mathrm{V}(\mathrm{t}))=\left(\rho_{\mathrm{r}} \frac{\mathrm{V}(\mathrm{t})}{\mathrm{V}\left(\mathrm{t}_{\mathrm{m}}\right)}+\rho_{\mathrm{o}}\right)
$$

where $t_{m}$ is time of end ejection.

Ventricular pressure is given by

$$
\mathrm{p}(\mathrm{t}, \mathrm{V})=\gamma_{\mathrm{s}} \cdot \mathrm{f}(\mathrm{t}) \cdot\left[\mathrm{V}(\mathrm{t})-\mathrm{V}_{\mathrm{e}}(\mathrm{t})-\mathrm{V}_{\mathrm{d}}\right]
$$

At end ejection Elastance is deactivated by a factor $a$ $(\leq 1)$ which has been shown [4] to be equal to

$$
\alpha=\alpha_{\mathrm{R}} \frac{\mathrm{p}\left(\mathrm{t}_{\mathrm{m}}\right)}{\mathrm{p}_{\mathrm{iso}}\left({ }_{\mathrm{t}}\right)}+\alpha_{\mathrm{o}}
$$

where $p_{\text {iso }}$ is isovolumic pressure at the end ejection volume involved.

Time dependence $f(t)$ was found from experimental isovolumic pressure according to:

$$
\left.\mathrm{f}(\mathrm{t})=\mathrm{p}^{*} \text { (iso }\right) /\left(\mathrm{V}\left(\mathrm{t}_{\mathrm{m}}\right)-\mathrm{V}_{\mathrm{d}}\right)
$$

The quantities $\mathrm{V}_{\mathrm{d}}, \gamma_{\mathrm{e}}, \rho_{\mathrm{r}}, \rho_{\mathrm{o}}, \gamma_{\mathrm{s}} \alpha_{\mathrm{R}}$ and $\alpha_{\mathrm{o}}$ are identified by fitting equations (1) through (5) to experimental pressure time courses $\mathrm{p}^{*}(\mathrm{t})$ (Simplex method).

\section{METHODS}

Experimental pressure-time courses were obtained from isolated rabbit ventricles afterloaded to constant ejection flow by external pumping. Amplitudes, time of onset and duration of the constant flow periods were experimental variables. Ventricular pressure was measured with a catheter tip pressure transducer. Data acquisition was performed by sampling the pressure and piston position signals with a 12 bits $\mathrm{AD}$ converter at maximally $1 \mathrm{kHz}$. 


\section{RESULTS}

Fig. 1 shows the quality of the fitting results for four different versions of the above model. In Case $M$ both $\alpha$ and $\rho_{\mathrm{r}}$ have been forced to fixed values, 1 and 0 respectively, representing both no deactivation and volume independent resistance. Cases $M V$ and MD represent either $\alpha=1$ or $\rho_{\mathrm{r}}=1$ respectively. Case MVD is the full model.

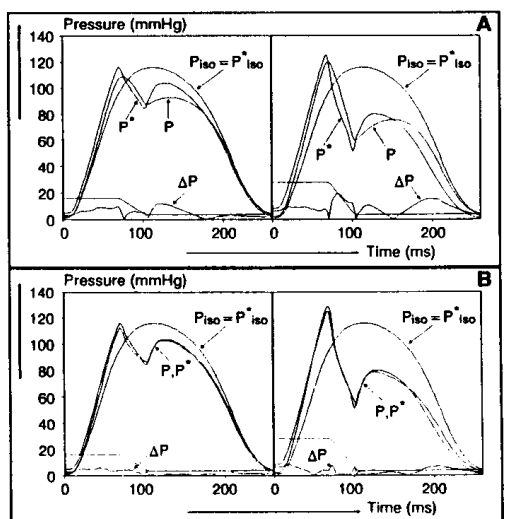

Figure 1 Results of model fitting on two CFP beats with dif ferent ejection parameters. $p^{*}$ : measured pressure, $p$ : simulated pressure $\Delta p=\left|p^{*}-p\right|, \quad p_{i s o}$ : isovolumic pressure.

Panel A: the model without deactivation. Bad fit quality. Panel B: the model with deactivation. Satifactory fit quality.

The figure shows that $\alpha<1$ is required for the model to fit correctly. Volume dependencies can be left out: both MD and MDV fit accurately $\left(\rho_{\mathrm{r}}=0\right)$.

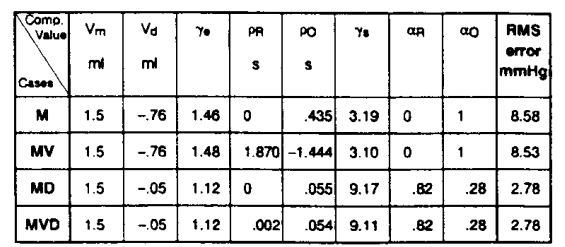

Table 1 Estimated values of model parameters. The cases $M D$ and $M V D$ have both low RMS error, indicating that deactivation is necessary for a food fit. Flow duration of the two beats used: $33 \mathrm{~ms}$. Flow values 9 and $18 \mathrm{~m} / \mathrm{s}$.
Table 1 summarizes parameter values identified. Forcing $\alpha=1$ not only causes a higher RMS error but also affects other values e.g. $\gamma_{e}$ and $\rho_{r}$ which then both are overestimated. Residual volume also markedly differs. Cases $M$ and MV are mutually different as to their sensitivity for volume dependence of $\rho$. Cases MD and MVD, incorporating deactivation are not. We conclude that the five-element model accurately describes the constant flow response of the ventricle. Moreover deactivation $(\alpha<1)$ is essential for a good fit. Resistance can be considered volume independent.

\section{DISCUSSION}

The five element model can only be expected to correctly estimate left ventricular ejection parameters for constant ejection flow. While increasing flow does not influence deactivation [5]. decreasing flow does, as was assumed in the present model since deactivation is switched on at the end of the constant flow period. To adequately describe physological flow one additional step is required: establishing the degree of deactivation at any moment that flow is decreased from a non zero value to a smaller non zero value.

There has been some controversy regarding a possible volume dependence of the resistance [2],[6]. The current study shows that if the model is used for estimating parameters including flow dependent resistance, volume dependence is not found. This is an attractive property: in the case $\rho_{r}=0$, the differential equation of which (1) is the discretized form can then be solved analytically and a quantitive description of ejection dynamics in closed analytical form is available.

\section{REFERENCES}

[1] H. Suga, K. Sagawa. Circulation Research, 35, 1974, $117-125$

[2] S.R. Vaartjes, H.B.K. Boom. Circulation Research, 60, $1987,12 \mathrm{pp}$.

[3] P. Schiereck, H.B.K. Boom. Pflügers Archiv, 374, $1978,135$.

[4] H. Wijkstra. The flow pulse response of the ventricular pressure source, Ph.D. Thesis, Enscheden, The Netherlands 1989.

[5] H. Wijkstra, H.B.K. Boom. Deactivation in the rabbit left ventricle induced by constant ejection flow. Acceptes for publication: IEEE Trans. on Biomed. Eng.

[6] S.G. Shroff, J.S. Janicki, K.T. Weber: Evidence and quantitation of left ventricular systolic resistance. Am J. Physiol. 249: H358-H370; 1985.

IEEE ENGINEERING IN MEDICINE BIOLOGY BOCIETY 11TH ANNUAL INTERNATIONAL CONFERENCE--0127 